\title{
Influence of Microwaves Irradiation on Modification of Oxetane Based Polymers with 4-(2-Amino-ethyl)morpholine
}

\author{
Nicolae Hurduc, ${ }^{\dagger}$ Jean-Marc Buisine, ${ }^{*}$ Patrick Decock, ${ }^{* *}$ Jacky Talewee, ${ }^{* *}$ \\ and Gheorghe SuRPATEANU** \\ Technical University "Gh. Asachi”, Department of Macromolecules, Bd. Copou IIA 6600-Iasi, Romania \\ * Laboratoire de Dynamique et Structure des Matériaux Moléculaires, U.R.A. C.N.R.S. no. 801 \\ Equipe de Thermophysique de la Matière Condensée. Université du Littoral, Quai Freycinet 1, \\ B.P. 5526, 59379 Dunkerque, France \\ ** Laboratoire d'Analyses et Chimie sous Hyperfréquences, Université du Littoral, \\ Quai Freycinet 1, B.P. 5526, 59379 Dunkerque, France
}

(Received September 27, 1995)

KEY WORDS Microwaves / Oxetane / Amino-Morpholine / Ring Opening / Polymer Modification /

In our previous work, the synthesis of some polyethers and polyesters by phase transfer catalysis technique, was presented. ${ }^{1-5}$ Such polymers were obtained by polycondensation reactions between 3,3-bis(chloromethyl)oxetane (BCMO) and various bisphenols or, diacids, some showing liquid crystalline (LC) behavior. ${ }^{2,4,5}$ The posibility of modifying these polymers in the presence of triflic acid was also reported. This method can generate non linear-optic materials. ${ }^{6}$

Microwave (MW) irradiation (continuous or pulsed) mode dependence on the diglycidyl-ether of bisphenol-A crosslinking kinetics, in the presence of diaminodiphenylmethane, has been mentioned. ${ }^{7,8}$ Microwave treatment of the reactive epoxy mixture was carried out through a wave guide line acting on a polarized electrical field at frequency of $2.45 \mathrm{GHz} .^{9}$

By combining ring opening of the oxetane groups with microwave-induced functionalization, the present paper discusses the modification and characterization of oxetane-based polymers with 4-(2-amino-ethyl)morpholine (AEM). To the authors knowledge, no literature data exist on linkage by ring opening of oxetane polymers upon microwave irradiation.

\section{EXPERIMENTAL}

The microwave reactor $(150 \mathrm{~mL})$, equipped with condenser, was placed inside a specially designed oven coupled to a universal generator $(2.45 \mathrm{GHz})$, a stereo- mode applicator, a two-stub impedance adapter and a thermovision 870 IR camera. Temperature was recorded with a PC-AT-386 computer connected to the camera.

Characterization of the polymers was performed by ${ }^{1} \mathrm{H}$ NMR spectroscopy (BRUKER-300 MHz), differential calorimetry (SEIKO DSC 220) and polarized light microscopy (LEITZ DM RXP microscope).

The synthesis of the basic-polymer, containing oxetane rings in the main chain, was previously reported. ${ }^{1}$ This polyether was synthesized starting from BCMO and bisphenol-A, using a phase transfer catalysis technique. Low molecular weight samples were used to eliminate solubility problems.

In a typical transformation reaction of this polyether, $0.1 \mathrm{~g}$ of polymer $\left(M_{n}=3500\right), 0.1-1.0 \mathrm{~g}$ 4-(2-aminoethyl)morpholine (AEM) and $N, N$-dimethylformamide (DMF) $(10 \mathrm{~mL})$, were exposed to microwave irradiation at $200-800 \mathrm{~W}$ for $1-3$ hours. The reaction mixture was then cooled and precipitated in methanol, under stirring. The resulting solid was washed 5-6 times with methanol, and dried in a vacuum oven at $50^{\circ} \mathrm{C}$ for 48 hours.

AEM and DMF-Aldrich p.a. quality-were used without further purification.

\section{RESULTS AND DISCUSSION}

Transformation takes place as follows:<smiles>[3H]C(C)([IH+])CC1(COc2ccc(C(C)(C)c3ccc(OC(C)(C)C)cc3)cc2)COC1</smiles>

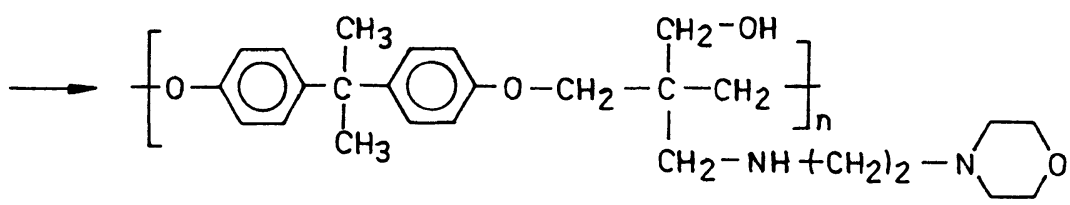

\footnotetext{
$\uparrow^{\dagger}$ To whom correspondence should be addressed.
} 


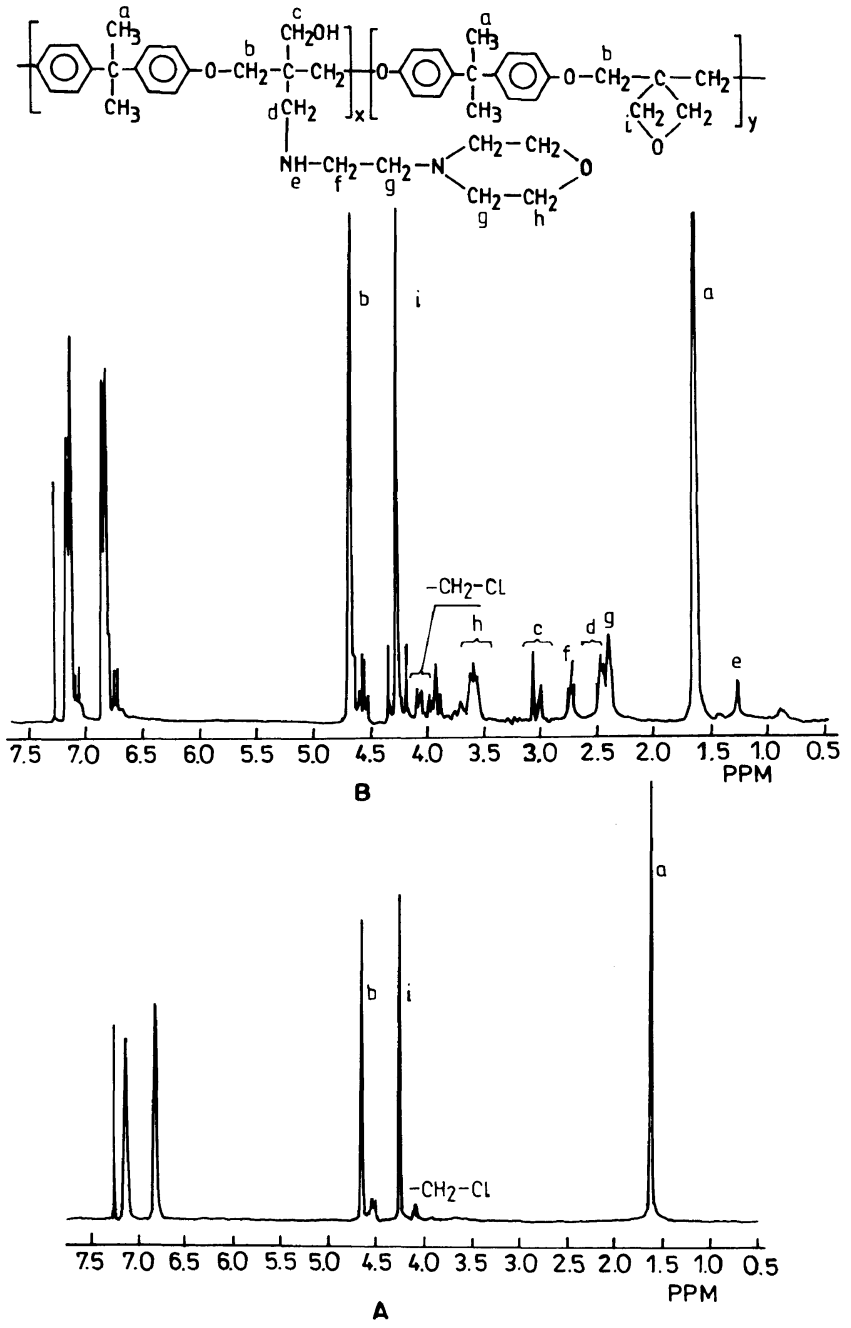

Figure 1. ${ }^{1} \mathrm{H}$ NMR spectra of unmodified (A) and modified (B) polyethers.

Different syntheses were performed by varying

- ratio between the polymer and AEM

- reaction time

-irradiation power

In some cases, at microwave irradiation at $200-800 \mathrm{~W}$ for $1-3$ hours, opening of the oxetane rings, followed by attachment of AEM, was observed. ${ }^{1} \mathrm{H}$ NMR analysis showed linking of AEM to the polymer chain. ${ }^{1} \mathrm{H}$ NMR spectrum $\left(\mathrm{CDCl}_{3}\right)$ of $\mathrm{AEM}$ presents the following chemical shifts: s, 1.29 ppm; $\mathrm{m}, 2.2-2.3 \mathrm{ppm}$; $\mathrm{t}, 2.6$ and $3.53 \mathrm{ppm}$. The basic polymer presents the following chemical shifts: s, $1.65 \mathrm{ppm}\left(-\mathrm{CH}_{3}\right) ; \mathrm{s}, 4.0 \mathrm{ppm}$ (terminal groups $-\mathrm{CH}_{2}-\mathrm{Cl}$ ); s, $4.25 \mathrm{ppm}$; and s, $4.65 \mathrm{ppm}$ (oxetanic rings); $\mathrm{m}, 6.70-7.1 \mathrm{ppm}$ for the aromatic rings (Figure 1A).

In Figure 1 are plotted the ${ }^{1} \mathrm{H}$ NMR spectra of the untransformed and transformed polymers (irradiated for $2.5 \mathrm{~h}$, without solvent).

Signals corresponding to both AEM and basic-polymer, and two new signals corresponding to the $-\mathrm{CH}_{2}-\mathrm{OH}$ groups appeared due to ring opening. Two signals $(2.95$ and $3.05 \mathrm{ppm}$ ) occur, because the oxetanic ring is present in the chain and terminal groups. Shifting of the aromatic signals, due to the open rings also takes place. The ratio of morpholine signals to amino signal $(1.35 \mathrm{ppm})$ reflects transformation of the $-\mathrm{NH}_{2}$ groups into $-\mathrm{NH}-$ groups.

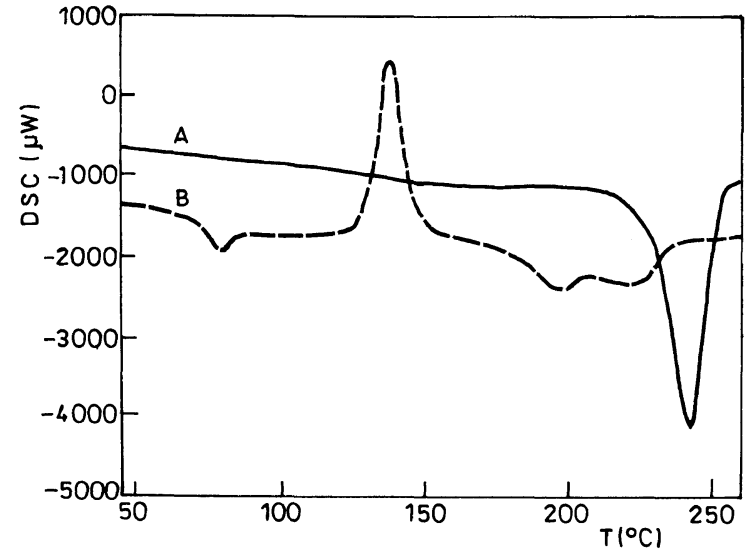

Figure 2. DSC thermogram of unmodified (A) and modified (B) polyethers.

The presence of two signals in the $2.3-2.5 \mathrm{ppm}$ region reported to the spectrum of AEM, reflects the formation of $-\mathrm{CH}_{2}-\mathrm{NH}-$ groups due to ring opening. The other signals in the $3.8-4.5 \mathrm{ppm}$ region are generated by terminally transformed groups and $-\phi-\mathrm{O}-\mathrm{CH}_{2}-$ groups connected to the transformed oxetane.

Transformation was estimated from ${ }^{1} \mathrm{H}$ NMR spectra, as the ratio of $-\mathrm{CH}_{2}-\mathrm{OH}(3 \mathrm{ppm})$ to $-\mathrm{CH}_{2}-\mathrm{O}-\mathrm{CH}_{2}-$ (oxetane, $4.25 \mathrm{ppm}$ ) groups, reflecting the ratio of the open to closed rings.

Polymerization degree before and after modification was the same $(n=11)$.

The thermal behavior also confirms polymer transformation. If the basic polymer presents only a melting point at $240^{\circ} \mathrm{C}$, (Figure $2 \mathrm{~A}$ ) the transformed product has $T_{\mathrm{g}}=71^{\circ} \mathrm{C}$, an exothermic signal at $130^{\circ} \mathrm{C}$ and two endothermic signals at $190^{\circ}$ and $225^{\circ} \mathrm{C}$ (Figure 2B). The basic polymer presents high crystallization capacity and, as a consequence, some difficulties appear, concerning $T_{\mathrm{g}}$ measurement by DSC; a sudden cooling after heating is necessary prior to this measurement. ${ }^{10}$ Modification of the polymer results in reduction of ordering capacity, due to the presence of morpholine groups in the side-chain. This polymer has higher content of the amorphous phase and measurement of $T_{\mathrm{g}}$ is therefore possible. At $130^{\circ} \mathrm{C}$, the untransformed chains crystallize, generating an exothermal signal. The double endothermal signal is probably due to double melting of the transformed and untransformed polymers.

This above was confirmed, by polarized optical microscopy.

Table I presents the influence of MW, solvent, temperature and reaction time on the degree of substitution. When employing a solvent, the concentration of AEM was $0.8 \mathrm{~mol} \mathrm{~L}^{-1}$.

Two syntheses have been developed, namely: in solution or directly in the AEM liquid. The degree of substitution is poor $(3.5 \%)$, when the solvent is DMF (temperature was $153^{\circ} \mathrm{C}$ ). In the latter case, a higher degree of substitution $(27 \%)$ was obtained at 2.5 hours of irradiation and power of $750 \mathrm{~W}$ (temperature was $200^{\circ} \mathrm{C}$ ). It is difficult to say whether the temperature or increase in amine concentration is responsible for this higher degree of substitution.

For comparison, several syntheses without MW ir- 
Table I. Effects of various parameters on the degree of substitution in a polymer

\begin{tabular}{|c|c|c|c|c|c|}
\hline \multirow{2}{*}{$\begin{array}{c}\text { No. } \\
\text { sample }\end{array}$} & & \multirow{2}{*}{ Solvent } & \multirow{2}{*}{$\frac{\text { Temp }}{{ }^{\circ} \mathrm{C}}$} & \multirow{2}{*}{$\frac{\text { Time }}{\mathrm{h}}$} & \multirow{2}{*}{$\begin{array}{c}\begin{array}{c}\text { Degree of } \\
\text { substitution }\end{array} \\
\% \%\end{array}$} \\
\hline & & & & & \\
\hline 1 & & $\mathrm{CHCl}_{3}+\mathrm{AEM}$ & 61 & 1.0 & 0 \\
\hline 2 & & & 61 & 3.0 & 0 \\
\hline 3 & Under & $\mathrm{DMF}+\mathrm{AEM}$ & 153 & 1.0 & traces \\
\hline 4 & MW & & 153 & 2.0 & 3.5 \\
\hline 5 & & AEM & 200 & 1.0 & 10.1 \\
\hline 6 & & & 200 & 2.5 & 27.0 \\
\hline 7 & & $\mathrm{CHCl}_{3}+\mathrm{AEM}$ & 61 & 3.0 & 0 \\
\hline 8 & Without & $\mathrm{DMF}+\mathrm{AEM}$ & 153 & 2.0 & 1.5 \\
\hline 9 & & AEM & 205 & 2.5 & 18.3 \\
\hline
\end{tabular}

radiation (in $\mathrm{CHCl}_{3}$, in DMF, or in AEM), were performed (Table I), all leading to smaller degrees of substitution.

When using diamines, one may expect to obtain tridimensional systems, with high mechanical resistance; if the bisphenols present long conjugated systems, these materials might generate nonlinear-optic properties.

\section{CONCLUSIONS}

1. A new means of oxetane ring opening under microwave irradiation, is reported.

2. This type of polymer modification is efficient to deplace the transitions temperatures. In the case of thermotropic liquid crystalline polymers, the method may be useful for modifying $T_{\mathrm{m}}$ and $T_{\mathrm{i}}$, as a function of substitution.

3. Taking into account the results obtained without MW irradiation, opening of the oxetanic ring occurs probably by a thermal mechanism, while microwaves favor reaction leading to higher substitution.

\section{REFERENCES}

1. C. I. Simionescu, V. Bulacovschi, and N. Hurduc, Revue Roum. de Chimie, 38, 1189 (1993).

2. N. Hurduc, V. Bulacovschi, A. Bordeianu, and C. I. Simionescu, Polym. Bull., 28, 639 (1992).

3. D. Scutaru, N. Hurduc, V. Bulacovschi, and C. I. Simionescu, Synthetic Polym. J., 1, 123 (1994).

4. N. Hurduc, V. Bulacovschi, D. Scutaru, V. Barboiu, and C. I. Simionescu, Eur. Polym. J., 29, 1333 (1993).

5. V. Bulacovschi, N. Hurduc, D. Scutaru, and C. I. Simionescu, J. Indian Chem. Soc., 71, 752 (1994).

6. Y.-L. Liu, G.-H. Hsiue, Y.-S. Chiu, and R.-J. Jeng, J. Polym. Sci., Part A, Polym. Chem., 32, 3201 (1994).

7. N. Beldioudi and A. Gourdenne, Eur. Polym. J., 24, 53 (1988).

8. N. Beldioudi and A. Bouazzi, Eur. Polym. Sci., 24, 49 (1988).

9. Ie Van Quang and A. Gourdenne, Eur. Polym. J., 23, 777 (1987)

10. N. Hurduc, D. Scutaru, A. Daoudi, J. M. Buisine, V. Barboiu, D. Vizitiu, and C. I. Simionescu, J. Macromol. Sci., in press. 